\title{
THE CHLORIDE, BASE AND NITROGEN CONTENT OF GASTRIC JUICE AFTER HISTAMINE STIMULATION
}

By W. SCOTT POLLAND, A. M. ROBERTS AND ARTHUR L. BLOOMFIELD

(From the Department of Medicine, Stanford University Medical School, San Francisco)

(Received for publication February 27, 1928)

In previous papers (1) the inadequacy of the usual test meal methods of studying gastric function has been discussed. It was pointed out especially that acid titration values obtained from specimens aspirated from the stomach after a test meal varied with an unknown factornamely, the speed of gastric emptying, and that in certain cases apparent absence of hydrochloric acid was due simply to neutralization by stomach contents. A procedure which obviated many of the variables of the older tests was introduced (2), but in order to obtain a still more accurate insight into the mechanism of gastric secretion further analysis of the constituents of the stomach juice seemed necessary. The object of the present work was to estimate, after a standard stimulus, the quantities of chloride, nitrogen and base which were secreted and to determine what, if any, aberrations from the normal occurred in cases of gastric disorder. In view of the observations of Bulger and Allen (3) presently to be discussed, it seemed of importance to find out whether deficiency of titratable acidity was due to an actual failure of chloride secretion or whether the mechanism for producing a relative deficiency of base was at fault. We also wished to determine whether any relation exists between the total amount of nitrogen in the gastric juice in health and in disease of the stomach and whether stimuli which affect acid secretion also influence the output of nitrogen.

The present report deals primarily with methods and with the findings in a miscellaneous group of hospital patients; special conditions such as "anacidity" will be discussed in future papers.

\section{LITERATURE}

Only a few thorough analyses of human gastric juice are to be found in the literature, probably because of the difficulty of obtaining satis- 
factory material. Carlson (4), working with people with gastric fistulae, sets down the following figures for the average composition of normal human stomach juice:

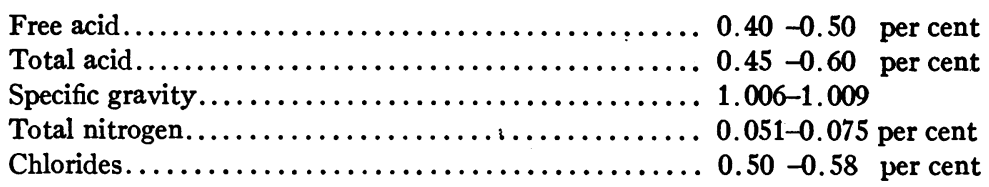

These figures are in essential agreement with those of other observers.

Baird, Campbell and Hern (5), and Miller and Smith (6) following Bolton and Goodhart (7) have studied the chloride content of specimens withdrawn after the fractional gruel meal used in clinical practice. The curve of chloride concentration as a rule follows that of the titratable acid at first but may continue to rise after the acid falls. This discrepancy has been interpreted as due to neutralization of acid by duodenal regurgitation or by alkaline pyloric secretion. As the analyses were not made with pure juice they are subject to all the errors which dilution by test meal introduces (1). This difficulty is avoided in the more recent observations of Berglund, Wahlquist and Sherwood (8) who examined the pure gastric juice obtained at intervals after histamine stimulation. They found a close correspondence between the curves of titratable $\mathrm{HCl}$ and chloride concentration and concluded that normal stomach juice contains only insignificant amounts of chlorine, if any, in other forms than hydrochloric acid. They also found an almost complete correlation between the highest chlorine figure of the gastric juice and the total base of the blood plasma.

Bulger and Allen (3) believe that chlorides are continuously secreted into the stomach at an approximately constant level and that increase in titratable acidity after stimulation is due to retention or resorbtion of base. This suggestion offers a further explanation for discrepancies in curves of free acid and total chlorides. As to actual determinations of base Gamble and McIver (9), working with gastric juice obtained from dogs with isolated gastric pouches, found that while the fasting juice showed an average ratio of acid (chloride) to base of 157 to 110 , after a meal there was little if any increase in chloride, whereas there was a marked fall in base, the ratio then being 164 to 30 . Material 
obtained from an isolated pyloric pouch yielded thick viscous material with a $\mathrm{pH}$ of 8.4. This secretion contained chloride in about the same proportion as the fundus juice and owed its alkalinity to a much larger content of fixed base.

We have found no references to determinations of nitrogen under conditions similar to those under which our observations were made.

The volume of gastric secretion has recently been discussed by Bloomfield and Keefer (10). With regard to titratable acidity, the wide variations to be found in health and in disease are well known (11). Suffice it to say that no observations are on record in which the acidity of the gastric juice far exceeds the equivalent value of the plasma base-approximately 150 to $165 \mathrm{~N} / 10$ per $100 \mathrm{cc}$.

\section{METHODS}

In planning the present experiments, any procedure in which a meal was to serve as stimulus for secretion seemed unsatisfactory. One immediately introduces the complication of dilution of gastric juice by test meal, and results which express the composition of pure gastric secretion cannot be readily obtained. The following procedure was finally adopted: The subject fasted for at least twelve hours and was examined in bed under standard basal conditions. A duodenal tube was passed for a distance sufficient to allow its tip to reach the most dependent part of the stomach. The patient was urged not to swallow saliva and this point was carefully emphasized throughout the test. As soon as the tube was in place the fasting contents were withdrawn with a syringe. Continuous aspiration was then begun and the subsequent gastric secretions were collected over ten-minute periods. The technique of such aspiration requires a great deal of practice if one is to approximate complete collections and avoid trauma to the stomach. One eventually develops a tactile sense which recognizes the varying phases of tone and relaxation which the fasting stomach exhibits (12). At best, collections made in this way are not invariably complete since fluid may pass out of the stomach while aspiration is being made. In the subsequent figures this reservation is implied, although the volumes are set down as total secretion for the various periods. It should also be remembered that we were working with a composite and possibly variable gastric secretion in so far as it was a mixture of juice from both fundus and pylorus. Another possible error is introduced by the presence of saliva or duodenal contents in the stomach at the beginning of the test, or by their entry into the stomach during the examination. In spite of this possibility it was decided not to lavage the stomach since this procedure in itself stimulates secretion and one cannot be sure of removing all the wash water. Bile was carefully looked for, and whenever it appeared we assumed that duodenal regurgitation had taken place. After the 
fasting secretion had been collected over one or more ten-minute periods, histamine, $0.1 \mathrm{mgm}$. per $10 \mathrm{kilos}$ of body weight, was injected hypodermically to stimulate secretion. The aspiration was continued for as many more periods as convenient. Regurgitation of duodenal contents (bile) led to premature termination of the experiment in certain cases.

The following observations were made on the various ten-minute specimens: (1) Volume; (2) Appearance, (3) Titratable acidity, (4) Concentration of chlorine, (5) Concentration of nitrogen, (6) Concentration of base. Nitrogen was determined by Kjeldahl, chlorine by Van Slyke's method (13), and base by the method of Stadie and Ross (14). All tests were run in duplicate except in a few instances in which the amount of material was insufficient. Checks against solutions of known composition were run from time to time. As only minute amounts of phosphate are present in gastric juice (15) Stadie and Ross' method seemed suitable.

\section{MATERIAL}

Our observations are based on a study of twenty-two subjects. They were all ward patients and for the most part presented no evidence of organic disease of the stomach, although several ulcer cases were included. The clinical diagnoses are given in table 1 . Volume, titratable acidity and chloride determination were made in every case; nitrogen determinations in nine cases and base determinations in nine cases. Table 2 shows a complete protocol of a single examination to illustrate the procedure, but most of the results are summarized in the following charts.

\section{RESULTS}

Volume of secretion. The total volumes of secretion per ten-minute period, in each case, before and after histamine are shown in chart 1. The figures are similar to those reported by others (16), but several points deserve comment. One is immediately impressed by the great differences in the volume of juice in different people even though the observations are made under standard conditions; the general character of the curves is, however, similar. In every case but one (no. 21) there was an increase during the first period after histamine and the output reached its maximum within twenty to thirty minutes. This tendency is well shown in the composite curve (broken line). After thirty minutes there was usually a rapid decrease in volume which at fifty to sixty minutes had fallen approximately to the pre- 
histamine level. The fact that the volumes of the specimens collected before histamine usually decreased requires explanation. It seems certain that the passage of the tube itself acts as a transient stimulus; as this influence subsides the volumes decrease to a "basal level." Also, the first or second ten-minute collection may be increased by residues of juice which were' not entirely removed when the fasting contents were withdrawn.

TABLE 1

Clinical diagnoses in cases which were studied

\begin{tabular}{|c|c|c|c|}
\hline Case number & Sex & Age & Diagnosis \\
\hline 1 & F. & 31 & Gastric ulcer \\
\hline 2 & F. & 41 & Migraine \\
\hline 3 & F. & 55 & Post-operative myxedema (mild) \\
\hline 4 & M. & 60 & Embryoma of testicle \\
\hline 5 & M. & 73 & Chronic constipation \\
\hline 7 & M. & 58 & $\begin{array}{l}\text { Severe anemia of long standing (not per- } \\
\text { nicious anemia) }\end{array}$ \\
\hline 8 & M. & 45 & Psychoneurosis \\
\hline 9 & M. & 55 & Gastric ulcer \\
\hline 11 & M. & 32 & Constipation \\
\hline 12 & M. & 37 & Duodenal ulcer \\
\hline 13 & M. & 30 & Duodenal ulcer \\
\hline 14 & M. & 38 & Chronic arthritis \\
\hline 16 & M. & 23 & Gigantism (slight) \\
\hline 17 & M. & 42 & Pyloric ulcer \\
\hline 18 & M. & 42 & Psychoneurosis \\
\hline 19 & M. & 55 & Duodenal ulcer \\
\hline 20 & M. & 35 & Duodenal ulcer \\
\hline 21 & M. & 24 & Psychoneurosis \\
\hline 22 & M. & 40 & Psychoneurosis \\
\hline 24 & M. & 29 & Hyperthyroidism (mild) \\
\hline 25 & M. & 33 & Amoebic dysentery (inactive) \\
\hline 27 & M. & 65 & Cancer of rectum \\
\hline
\end{tabular}

In a previous study (10), with alcohol as a stimulus, it was found that the ten-minute secretory volumes usually reached a maximum of not over $40 \mathrm{cc}$. and practically never exceeded $60 \mathrm{cc}$. It is of interest that even when one uses so powerful a stimulus as histamine a similar maximum seems to obtain. It appears also, that while the absolute increase in volume is not constantly related to the abundance of 
TABLE 2

Complete protocol of a typical experiment (case 20)

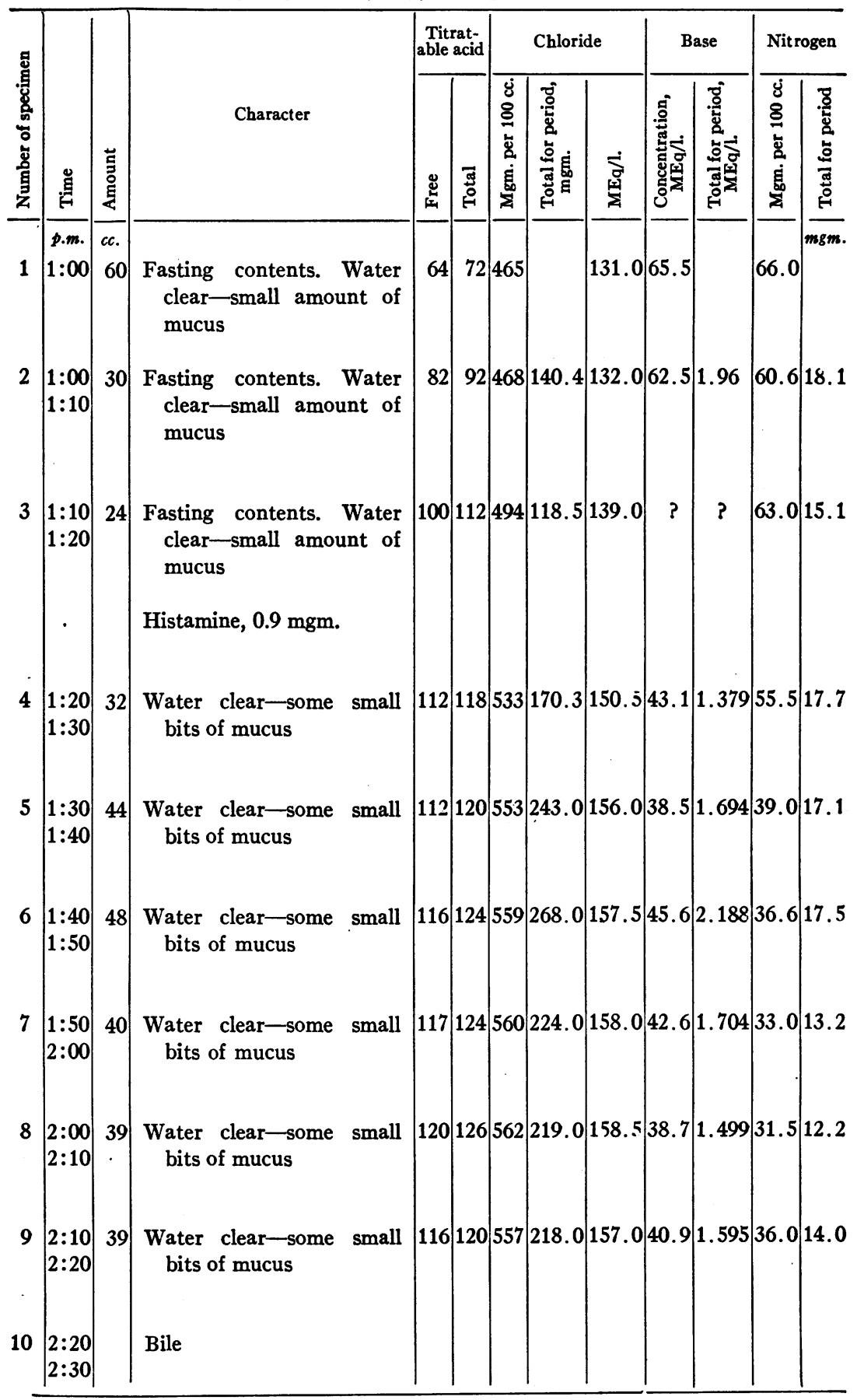


secretion before histamine stimulation, greater relative increases follow in cases with an initial low volume. Thus, in case 9, there was an increase from 31 to $60 \mathrm{cc}$., the volume being practically doubled by an absolute increase of $29 \mathrm{cc}$.; in case 5, on the other hand, there was an increase of $19 \mathrm{cc}$. to a maximum of six times the volume $(4 \mathrm{cc}$.) which was secreted in the period before stimulation.

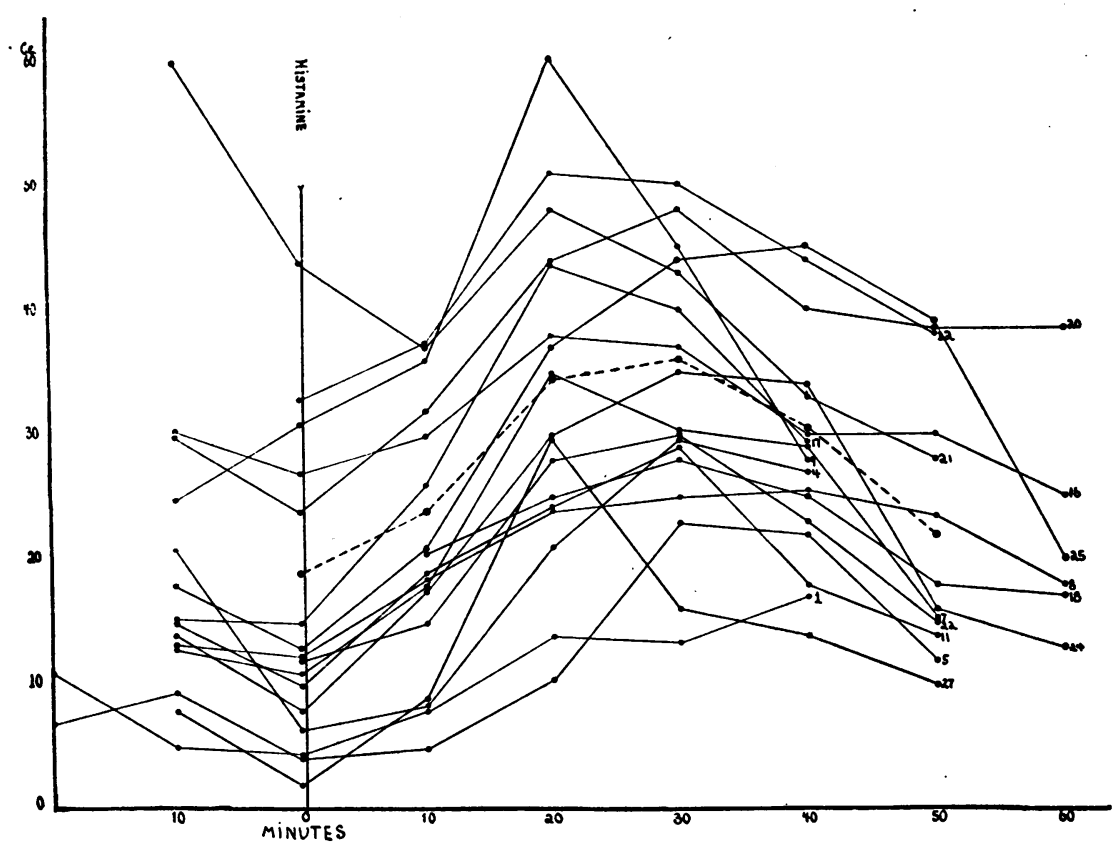

Chart 1. Curves Showing Volume of Secretion fór Ten-Minute Periods Before and After Injection of Histamme

\section{Chlorides}

Concentration of chlorides. Chart 2 shows the concentration of chlorides in the various ten-minute specimens from 15 cases. The general character of the curves is quite similar; beginning at a relatively low level there is a prompt rise which reaches its maximum in about twenty minutes. From this point on, the concentration remains practically constant (see composite curve-broken line). Later there is a tendency for the concentration to fall slightly. The 


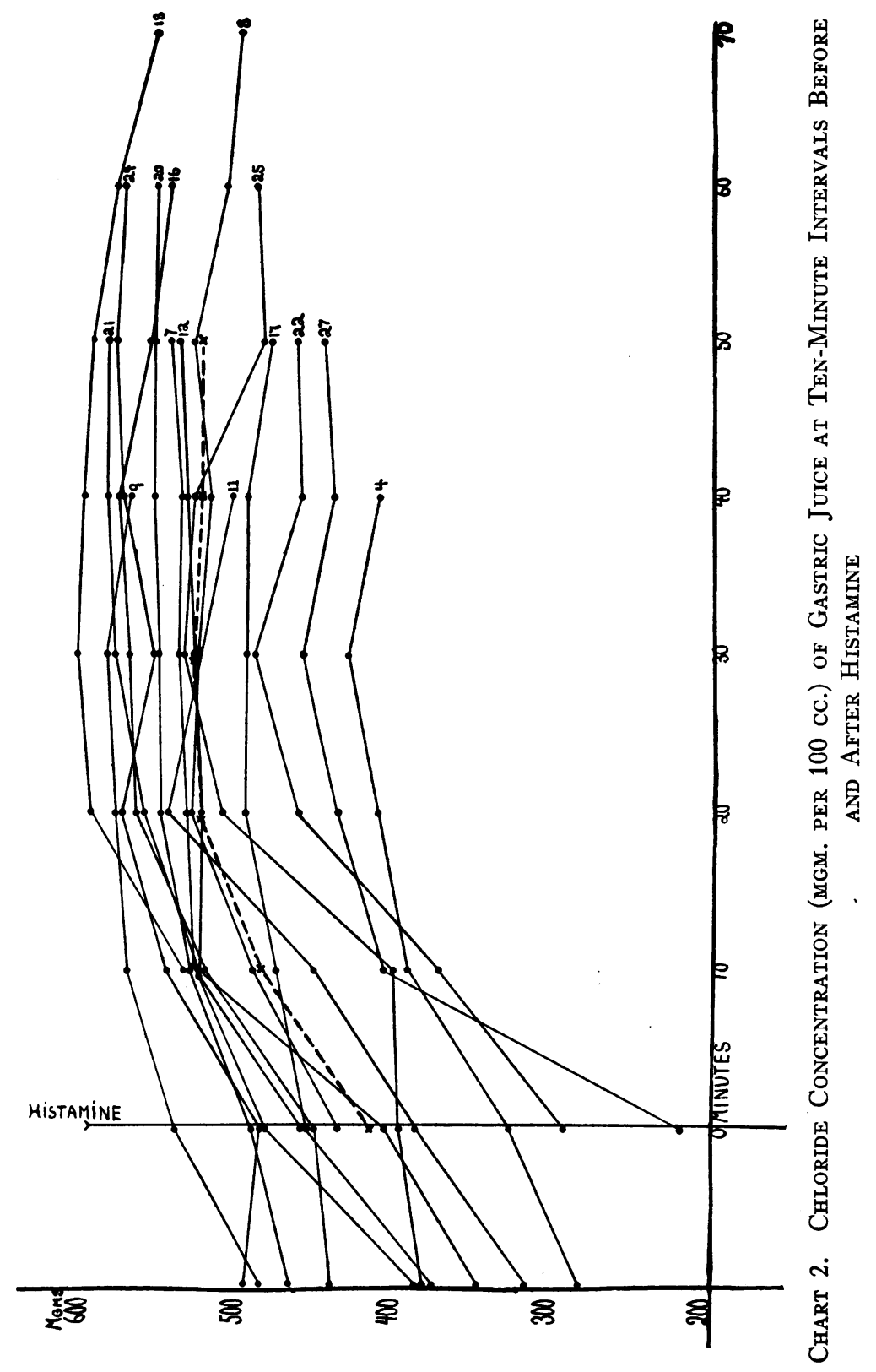


contrast, however, between the abrupt drop in volume of secretion and the sustained level of chlorides is well shown in chart 3 , in which the composite graphs of charts 1 and 2 are compared. The opinion has been expressed by Bulger and Allen (3) that the stomach secretes chloride at all times in practically constant concentration. This view would not seem to be supported by the initial phases of our curves which show a steep rise. It must be recalled, however, that we were dealing with mixed gastric juice. Before histamine stimulation the volume of gastric contents was usually small and there may have been

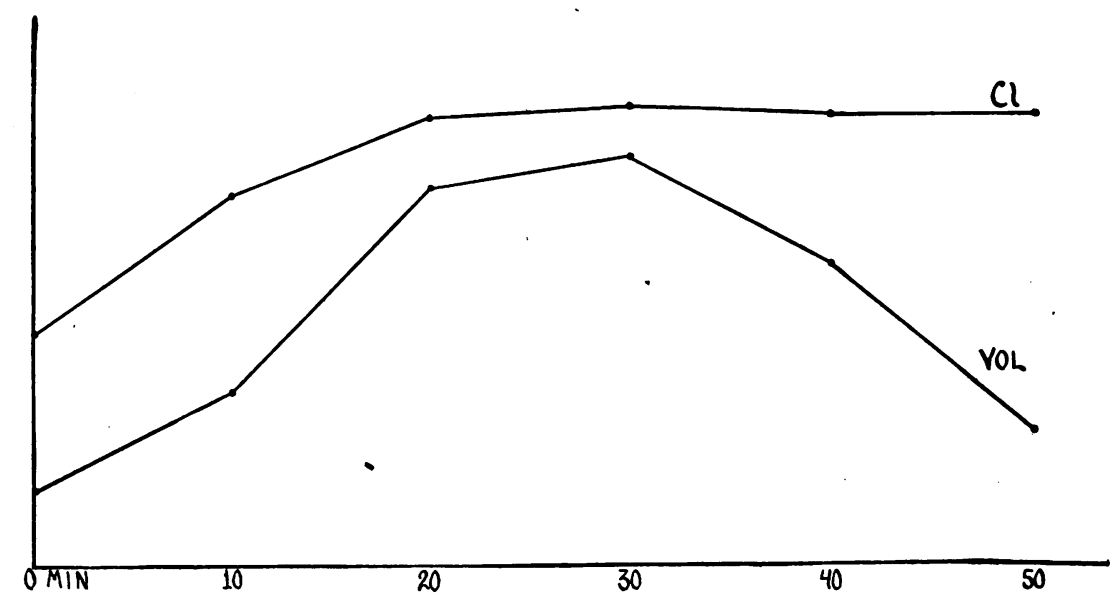

Chart 3. Composite Curves of Volume of Secretion and Concentration of Chlorme in Ten-Minute Specimens of Gastric Juice

relatively large amounts of secretion from the non-acid producing glands of the stomach as well as remnants of saliva, which diluted the chlorides. In case 27 , for example, the speciman obtained before histamine had a chloride concentration of only $220 \mathrm{mgm}$.; there were, however, only a few cubic centimeters of juice which consisted largely of mucus. Certain it is that even after the volume of secretion falls markedly the chlorides remain' high (compare curves of case 24 in charts 1 and 2), and even when the secretion is still more reduced by atropin there is only a moderate fall in chlorides which again can be well explained by dilution with non-acid secretion. The observations 
with atropin will be reported in another paper. On the other hand, variations in height of chloride concentration in different people clearly represent individual differences. No evidence to the contrary could be obtained from a study of other constituents of the gastric juice (nitrogen, base). Whether or not chloride always leaves the individual secreting cell at a constant concentration cannot be said,

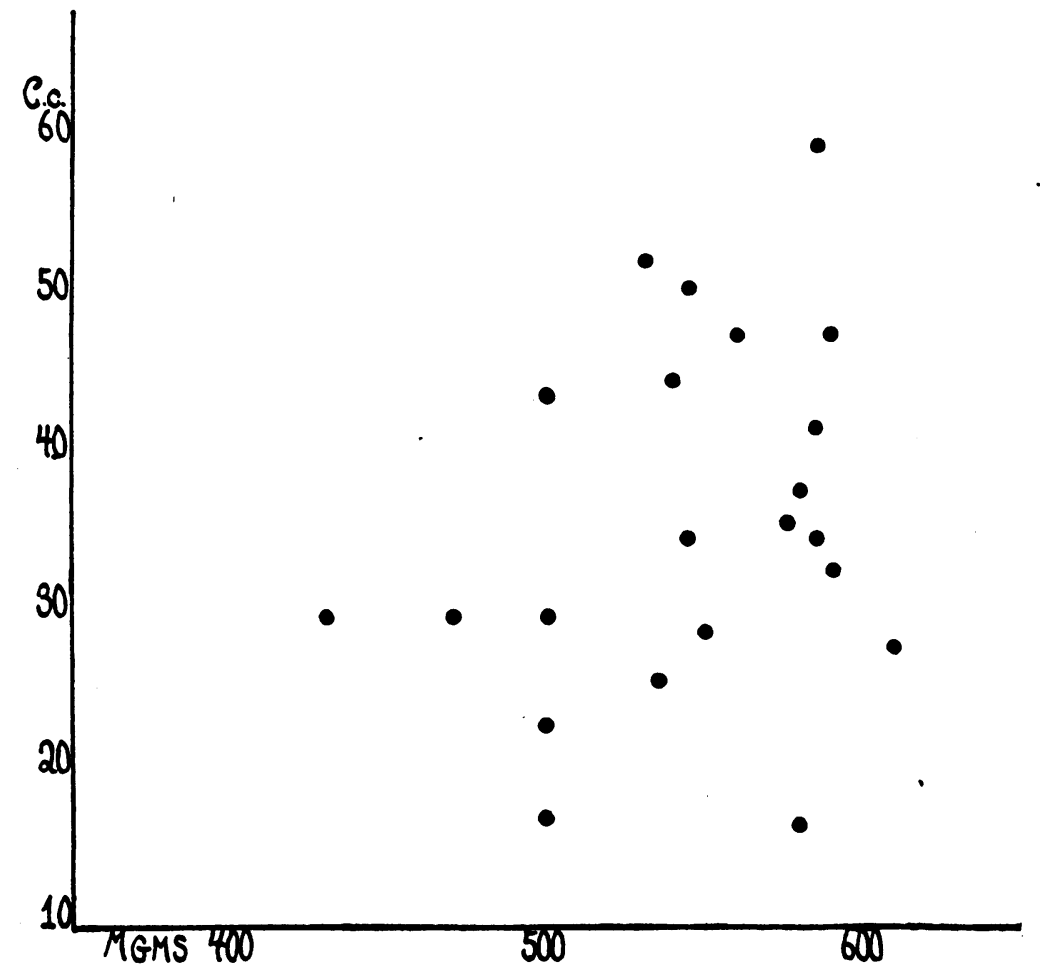

Chart 4. Relation Between Concentration of Chloride and Volume of Secretion of Gastric Juice

but in the juice, as poured into the stomach cavity, the differences in various people are beyond question.

In most cases a value of over $525 \mathrm{mgm}$. per $100 \mathrm{cc}$. was attained, the extremes being $435 \mathrm{mgm}$. (case 4) and $608 \mathrm{mgm}$. (case 18). As pointed out by Berglund the highest chloride figure approximates the total base of the blood plasma to which normal limits of 150 to 165 
cc. $0.1 \mathrm{~N}$ per $100 \mathrm{cc}$. have been assigned (17). Our high value of 608 mgm. is equivalent to $171 \mathrm{cc} .0 .1 \mathrm{~N}$ per $100 \mathrm{cc}$. On the other hand, our figures are not in accord with the statement of Bulger and Allen (3) that chloride is secreted at a concentration practically equal to that of the blood.

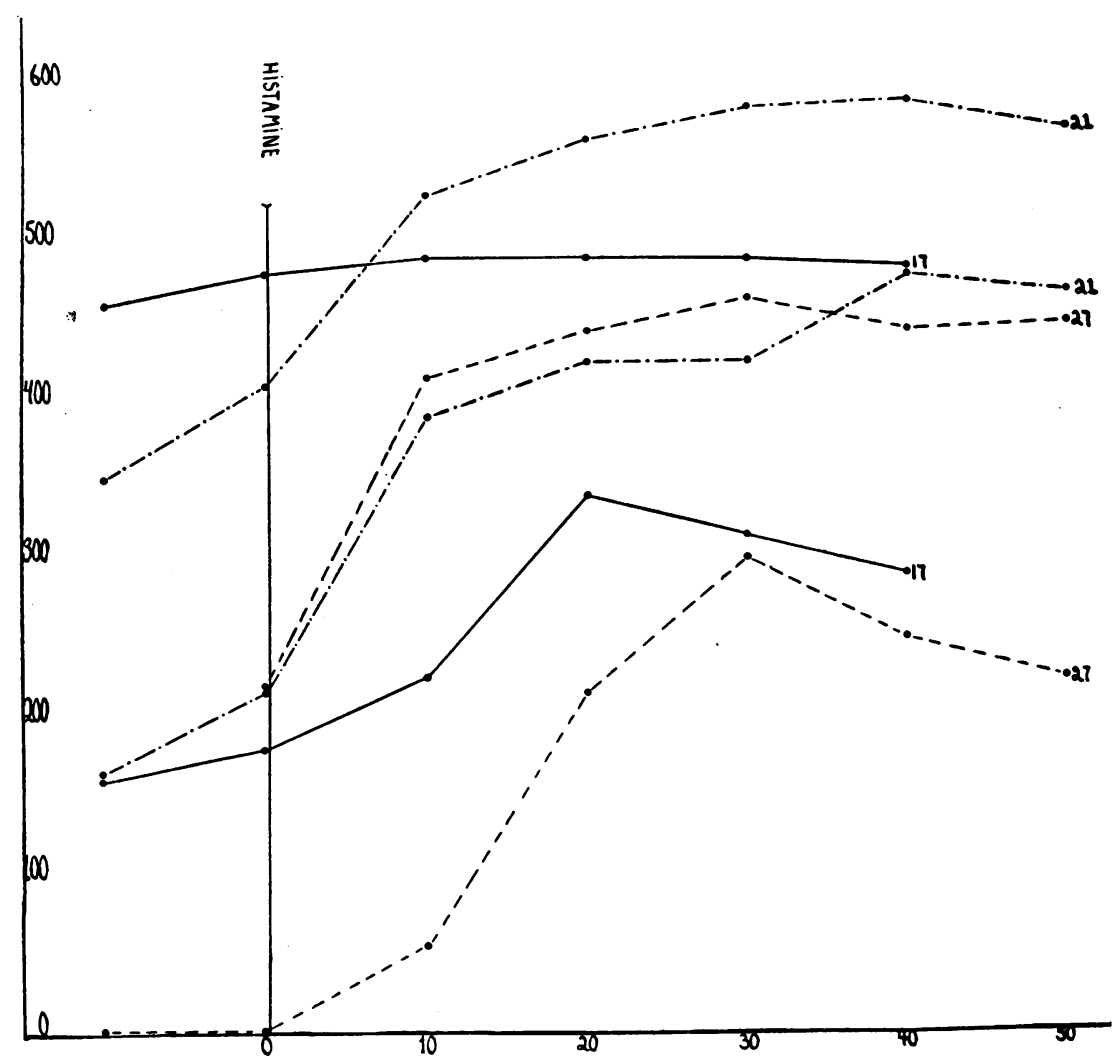

Chart 5. Curves of Chlorme Concentration Directly Determined and Calculated from Titratable Free Acid

Chart 4 shows the highest chloride concentration in various cases plotted against the volume of secretion for the corresponding period. No significant correlation can be made out, and it is evident that a large secretion implies neither high nor low chloride values except in a very general way. 
A study was next made of the relation of chloride to titratable acidity. Much stress has been placed on this question and the general implication of the literature $(5,6,7)$ is that titratable acidity gives no accurate picture of acid secreting ability of the stomach because of neutralization of chloride by alkaline duodenal contents. In the present experiments which lasted approximately one hour, there was no evidence of duodenal regurgitation insofar as presence of bile is an indication, and furthermore, we were working with pure gastric juice uncontaminated by test-meal or saliva. Under these conditions we found, as did Berglund et al. (8), that the curves of titratable acidity and total chloride were practically parallel. Chart 5 shows the results in three patients. The upper line in each case gives the total chloride, the lower the titratable acidity calculated as chloride. Chart 6 serves a similar purpose. Each dot of the lower set indicates the highest titratable chloride in a different case. Two instances of anacidity are included for comparison. The upper line gives the total chloride (concentration) in the corresponding cases. The total chloride exceeds the titratable by a fairly uniform amount regardless of whether the titratable acidity is high or low. In the first four cases, with little or no titratable acidity, the difference varies from 236 to $345 \mathrm{mgm}$.; in the remainder the difference varied between 97 and $196 \mathrm{mgm}$. In other words, under the conditions of these experiments the titratable acidity is a fairly accurate measure of the chloride secreting capacity of the stomach and gives a genuine indication as to whether the latter is high or low. We emphasize this point because of the stress which has recently been placed on the necessity of actually determining chlorides. The difference between total chloride and titratable chloride, of course, represents chloride in combination. That base as determined largely accounts for this difference will be shown later.

Total chloride. The concentration of chloride in the stomach juice gives only an incomplete picture of chloride secretion. Chart 7 shows the total output per ten-minute period. The great differences in different subjects are to be noted as well as the general similarity of form of the total chloride and volume curves (see chart 3). Chart 8

1 Throughout this paper titratable acidity refers to the number of cc. of $\mathrm{N} / 10$. $\mathrm{NaOH}$ necessary to neutralize $100 \mathrm{cc}$. of gastric juice with di-methyl as indicator. 
expresses some other relations of chloride secretion. Each dot in the lower line indicates the highest total output of chlorides per tenminute period in a different case. The upper line gives the concentra-

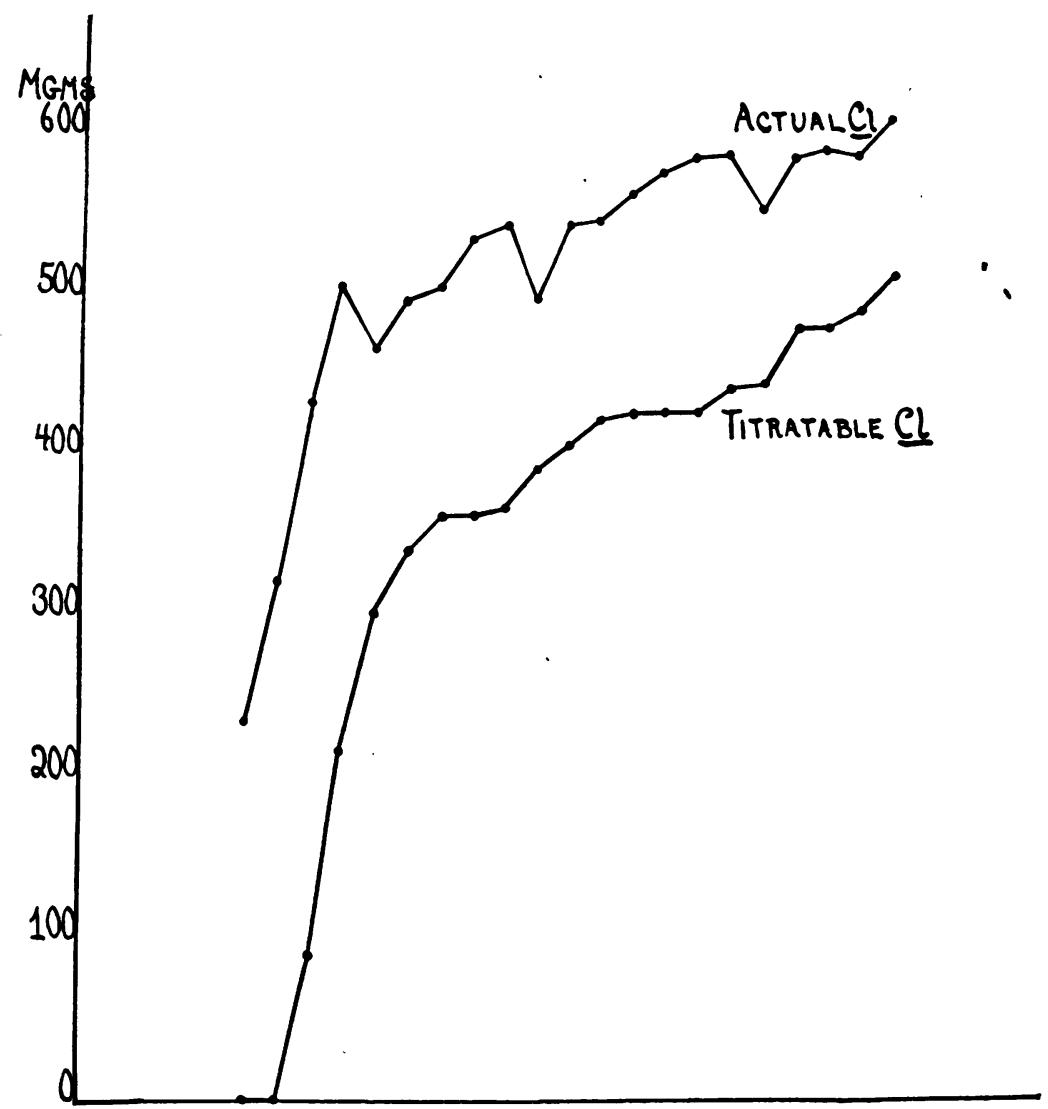

Chart 6. Chloride (mgm. per $100 \mathrm{cc}$.) Caiculated from Highest Titratable Acidity in Each Case (Lower Line) and Chloride as Actualiy

Determined by Analysis in Same Spectmens (Upper Line)

tion of chloride in the same specimens. When the total output is extremely low the concentration is also low but in the majority of cases there is no correlation between the two values. This chart 
expresses in another way the essential facts brought out in chart 4 . In brief, at a given concentration much or little chloride may be secreted.

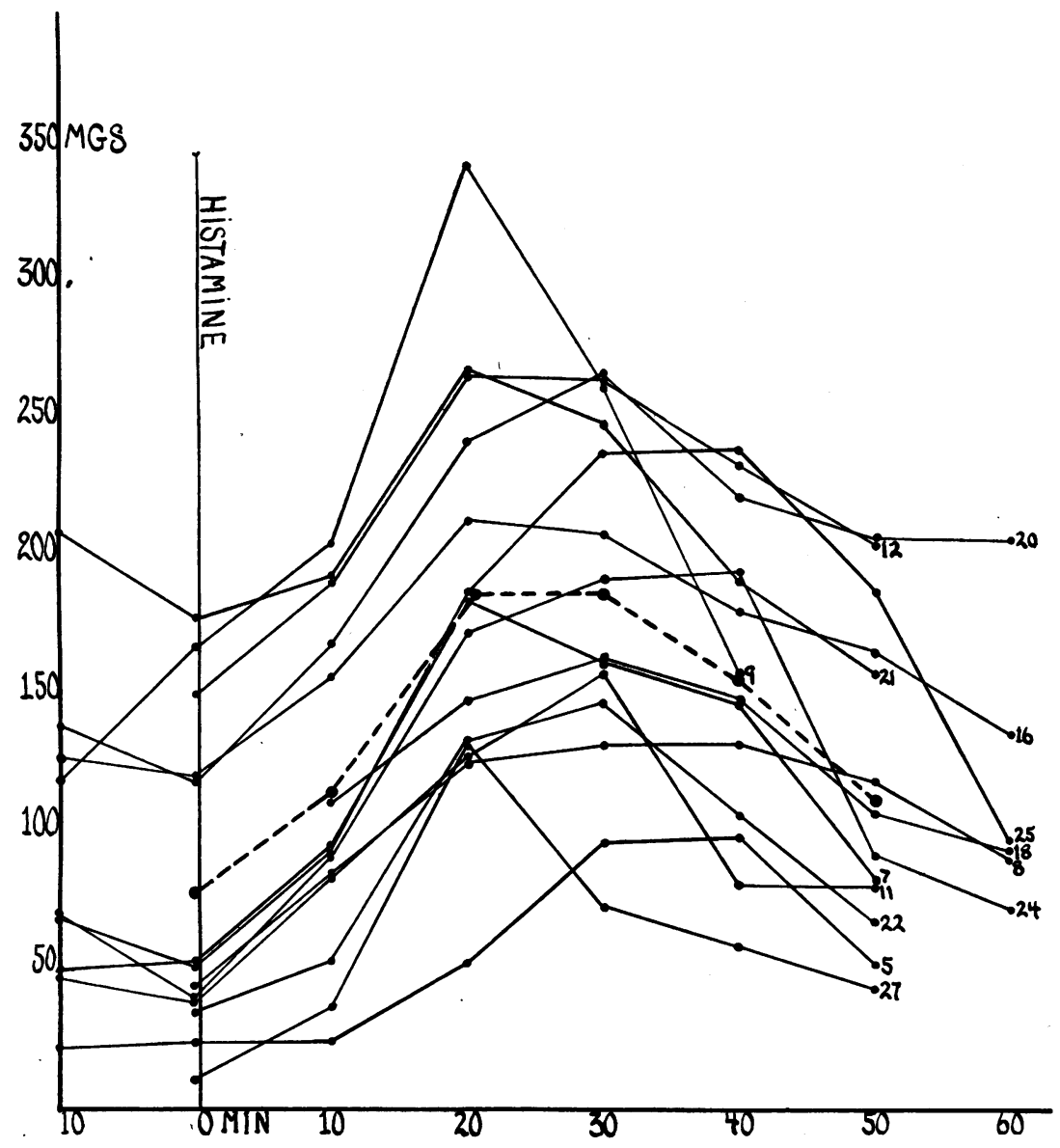

Chart 7. Curves Showing Quantity (mgm.) of Chlorme Secreted in Ten-Minute Periods Before and After Histamine

\section{Base}

The question of concentration of base may next be considered, and the figures for the various ten-minute specimens are presented in 
chart 9. The values in different cases are of the same general order of magnitude. The most striking point is that while base is relatively high before stimulation, it thereupon falls promptly and reaches a low

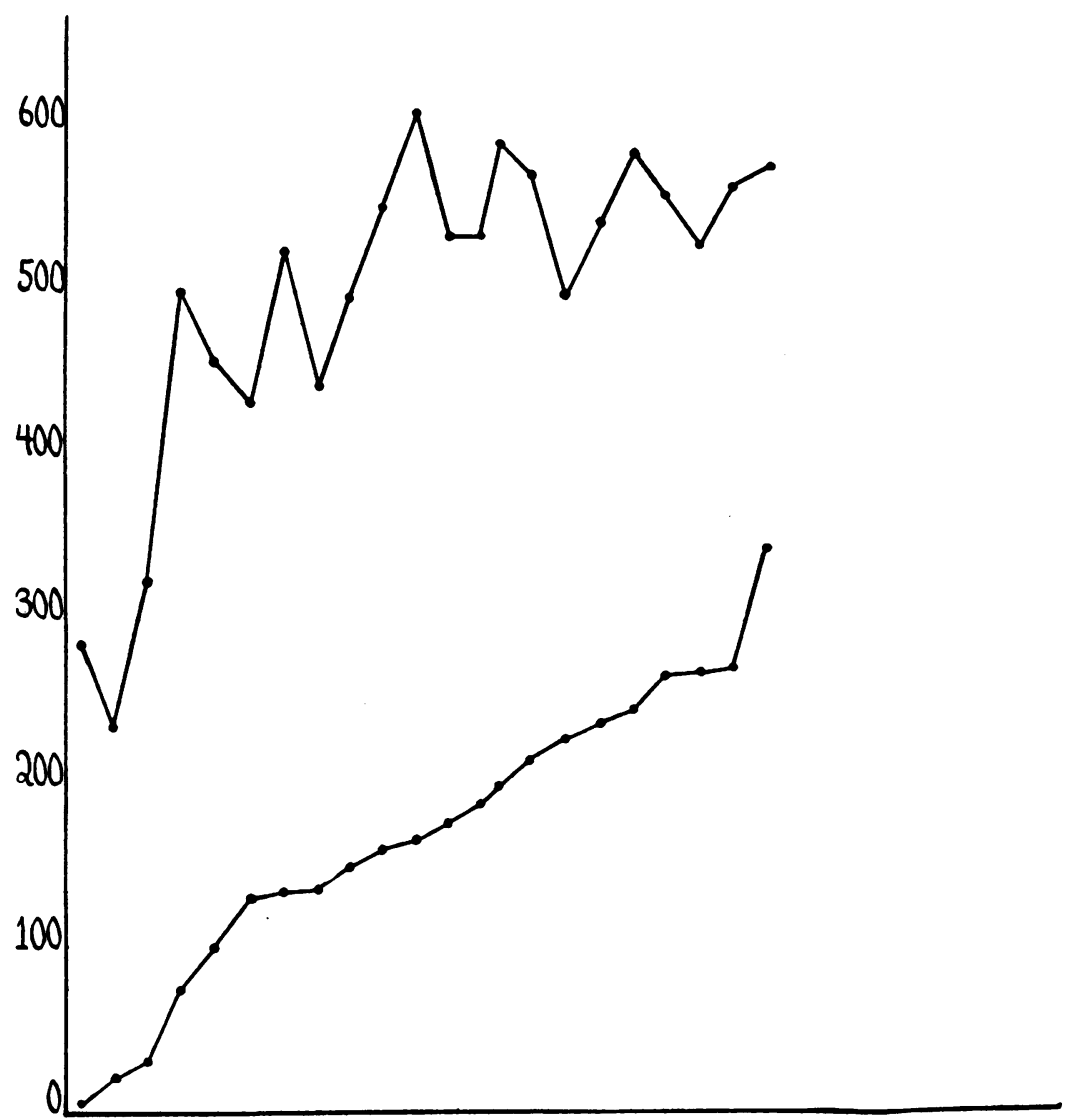

Chart 8. Total Output of Chloride (mgm.) per Ten-Minute Period in Each Case (Lower Line); Concentration of Chiordde (mgm. per 100 cc.) in SAMe Specmens (Upper Line)

point after about thirty minutes. This is well shown in the composite curve (broken line). In some cases (numbers 27, 22, 25) there was a rise toward the end of the experiment.

It seemed possible that the fall in base was due simply to dilution by 
increased secretion. That this explanation is untenable is indicated by chart 10 , in which the concentration of base (composite) in the six cases of chart 9, is shown together with a composite volume curve from the same cases. At first glance these curves seem to be the reverse of each other but further inspection shows that during the overlapping portion of their course both are falling. In brief, the concentration of base fell not only when volume of secretion was increasing but also

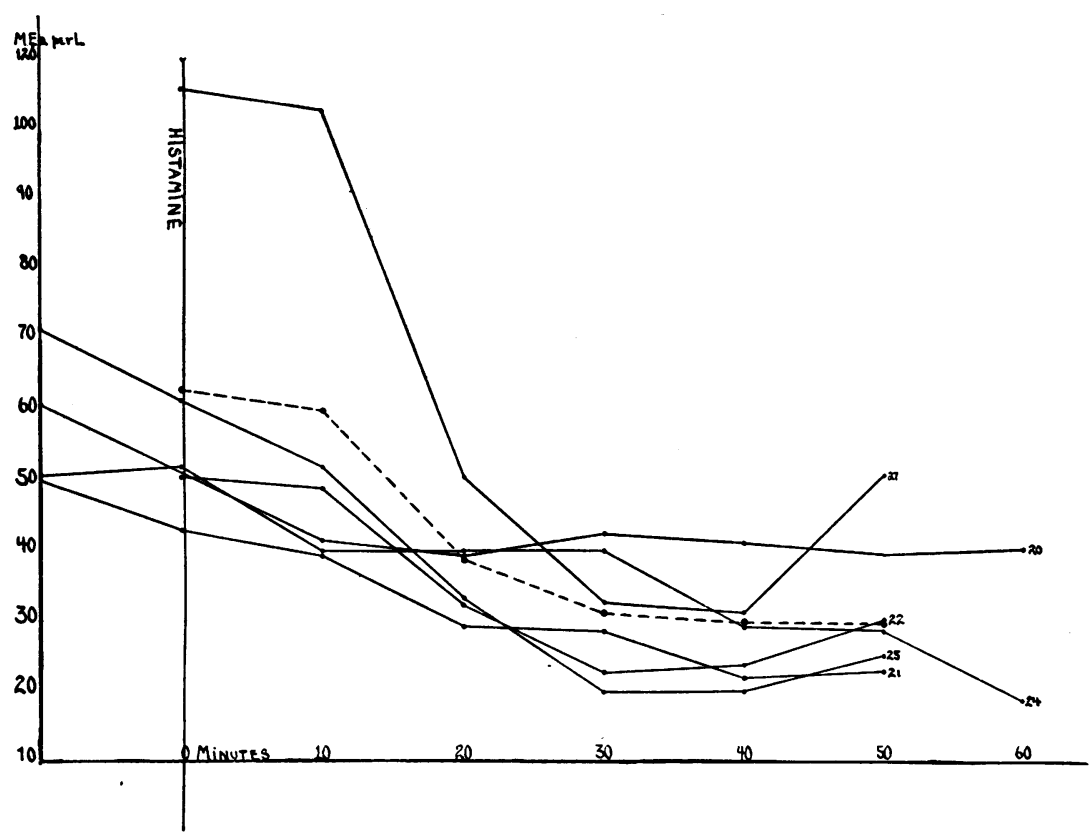

Chart 9. Concentration of Base (mEq. per Liter) of Gastric Juice at Ten-Minute Intervals Before and After Histamine

when it was decreasing. This rules out a mere dilution effect as do the observations depicted in chart 11, which shows the total quantity of base put out per ten-minute period. Here one sees that while the concentration falls the output increases after stimulation and that the total amounts vary considerably in different cases. They parallel quite closely the volume of secretion as may be seen by further reference to chart 10. It is clear, therefore, that the secretion of base is actively affected by histamine stimulation. The total output (broken 
line, chart 11) falls with fall in volume of juice without any corresponding rise in concentration within the limits of time of the present experiments. The concentration may rise later when the effects of stimulation have entirely passed and the volume of secretion is reduced to a minimum.

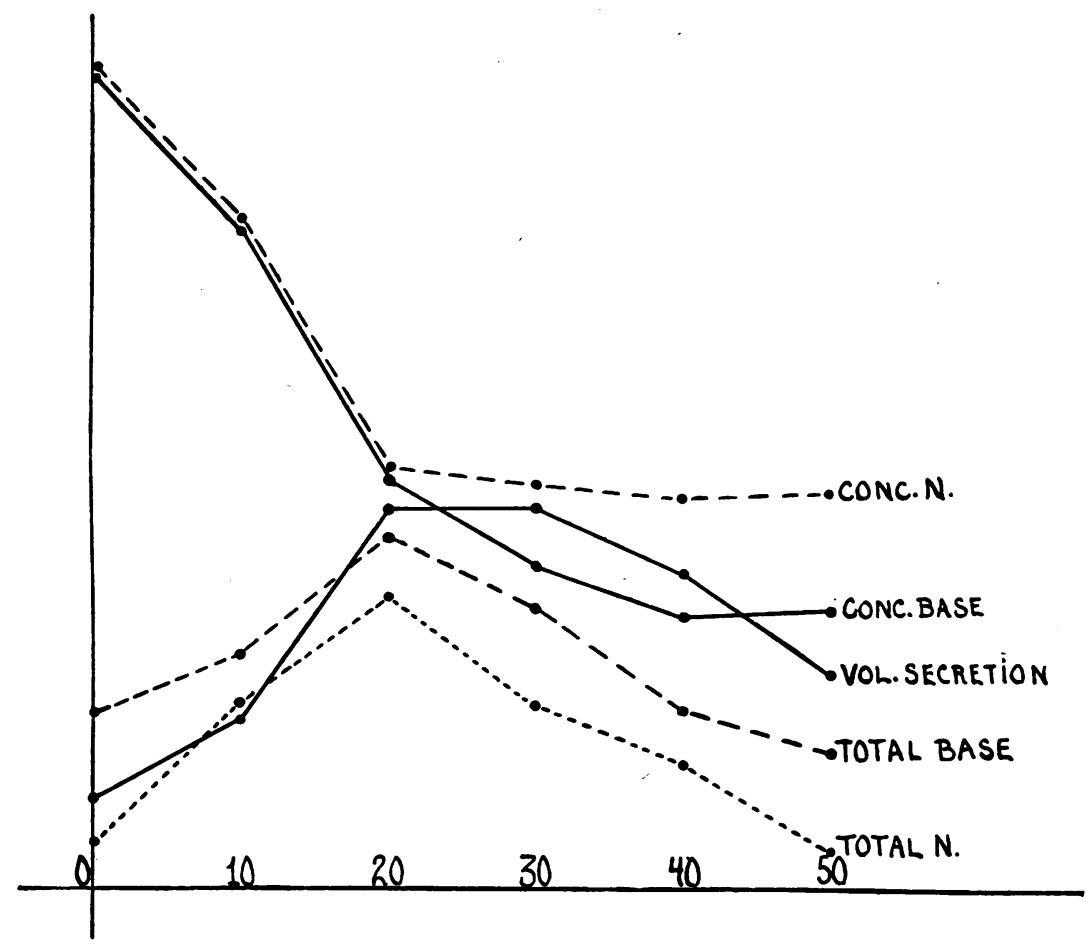

Chart 10. Composite Graph of Volume of Secretion (cc.), Total Base (mEq.) Concentration of Base (mEq. per Liter) Concentration of Nitrogen and Total Nitrogen in Ten-Minute Periods Before and After Histamine

Calculations were next made to find out to what extent the discrepancy between titratable and total chloride could be accounted for by base. The solid lines in chart 12 represent a composite calculation for the six cases shown in chart 9. The figures for the calculated acidity were reached by subtracting from the milliequivalents of chloride the milliequivalents of base for the corresponding periods. 
The "actual" acidity is that determined by titration with $\mathrm{N} / 10 \mathrm{NaOH}$ against dimethyl. When secretion is under way the calculated figures are uniformly higher than the "actual" and it is evident that the difference between titratable acid and total chloride is not completely accounted for by base, although the discrepancy is not large. The broken lines in chart 12 show the findings in a single representative

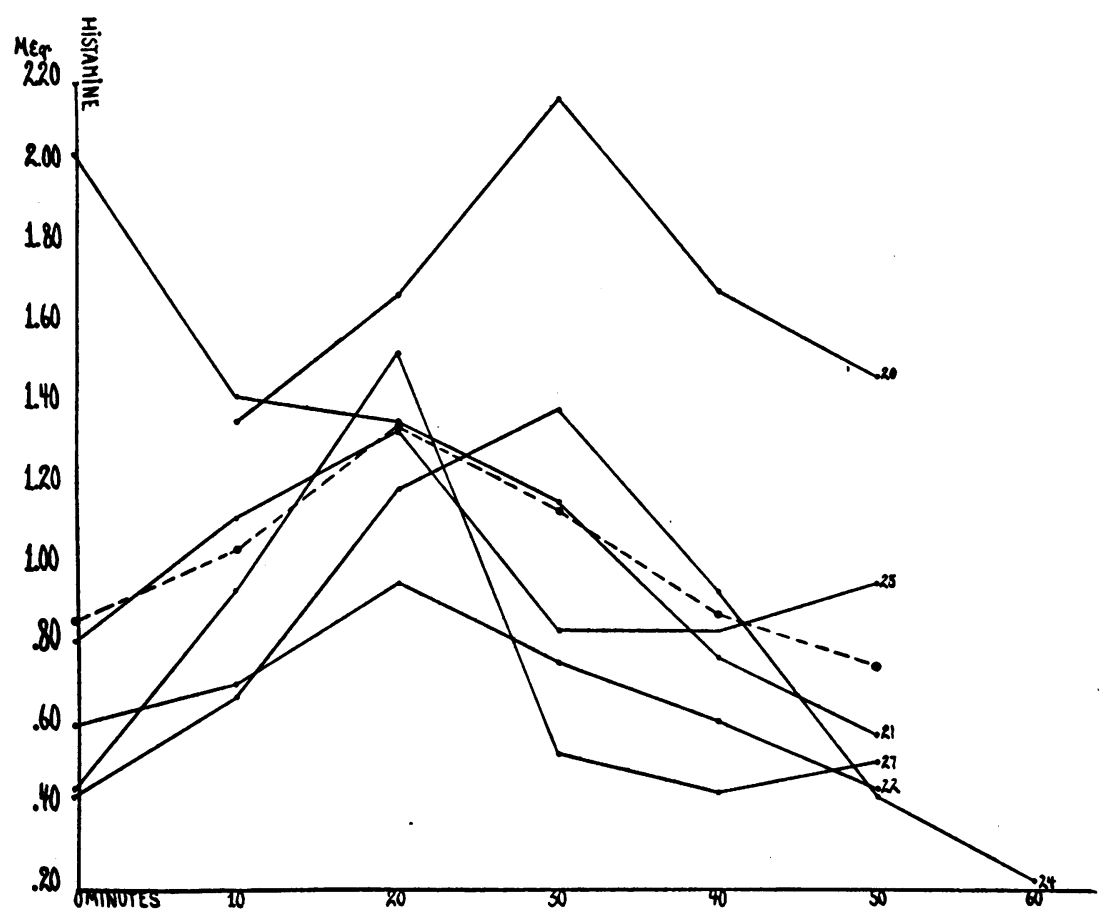

Chart 11. Curves of Total Base (mEq.) Secreted in Each Case in TenMinute Periods

case. The fact that actual is above calculated acid in the first part of the curve in chart 12 is due to the absence in some cases of titratable acid with dimethyl before stimulation; as there is no figure to express value less than zero an artefact is introduced. The slight discrepancy between the calculated and actual acidity must be due to some buffer substance, possibly protein. This point will be discussed below.

We may now consider the relations of acid and base during secretion. 
Charts $13 \mathrm{~A}$ and B show the course of events as regards concentration. The separation of the curves after stimulation, owing to rise in chloride and drop in base, is obvious. The crossing of the lines in case twentyseven indicates that the specimens were actually alkaline before secretion became marked. The numbers on the acid line refer to the titrat-

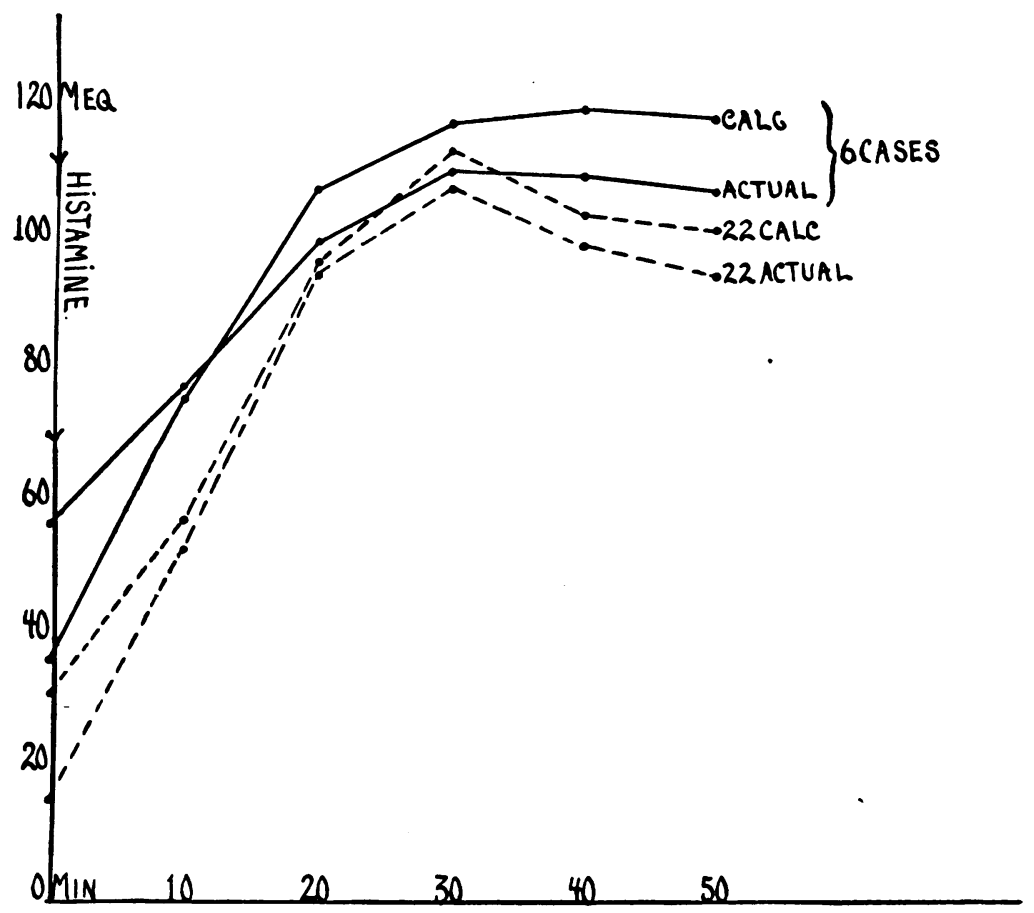

Chart 12. Graphs Showing Gastric Acidity as Determined by Direct Titration of Juice (Free HCl) and Acidity of Same Specimens Calculated by Subtracting Base from Chloride Concentration DeterMINED UPON SAME SPECIMENS

Shows curves from a single case (no. 22) and composite curves of six cases

able acidity at various points. Their failure to correspond exactly with the difference between acid and base is discussed in the paragraph above. Charts $14 \mathrm{~A}$ and $\mathrm{B}$ show the total quantities of acid and base secreted in ten-minute periods. In contrast to the preceding curves the total quantity of base increases even though the concentration 

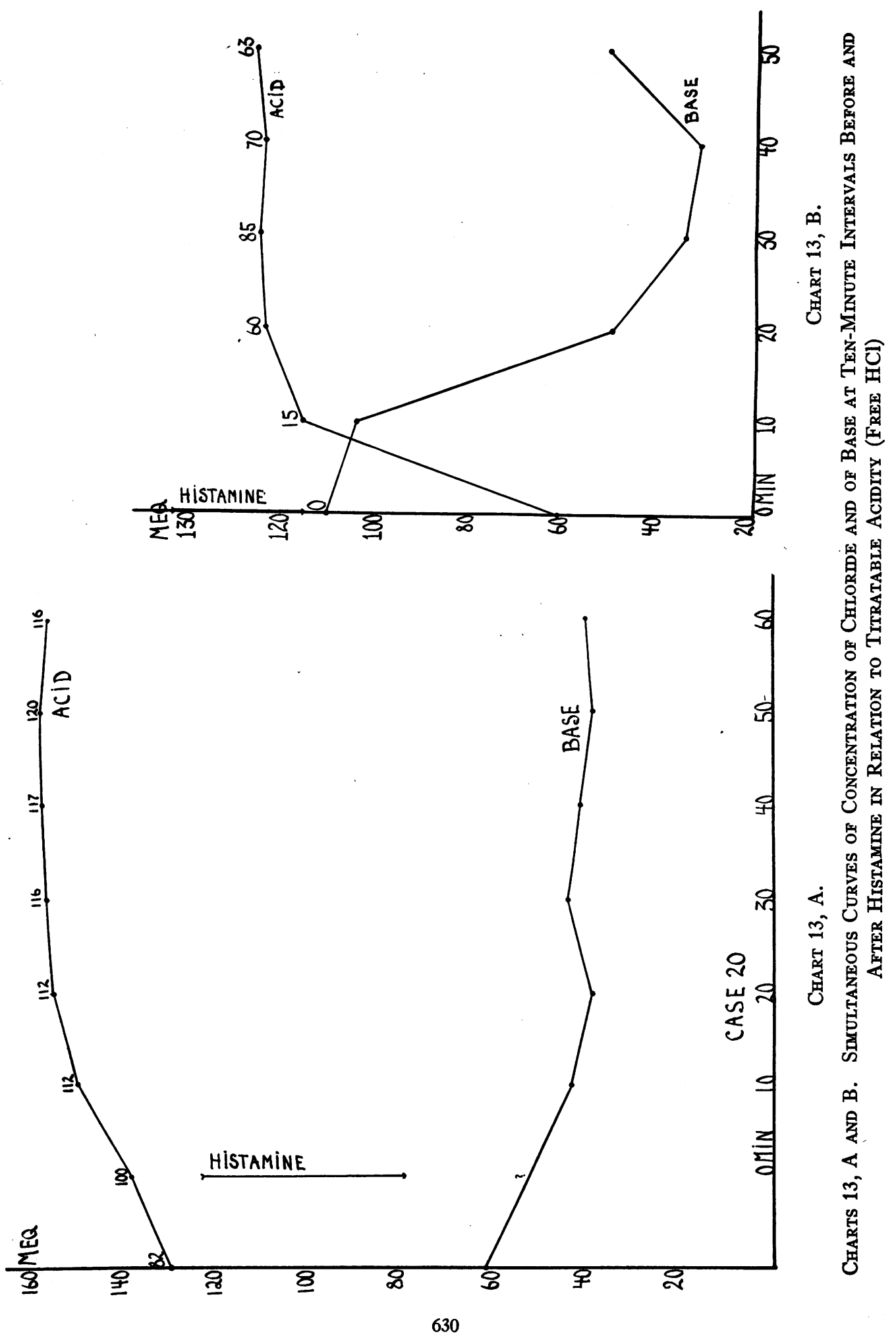


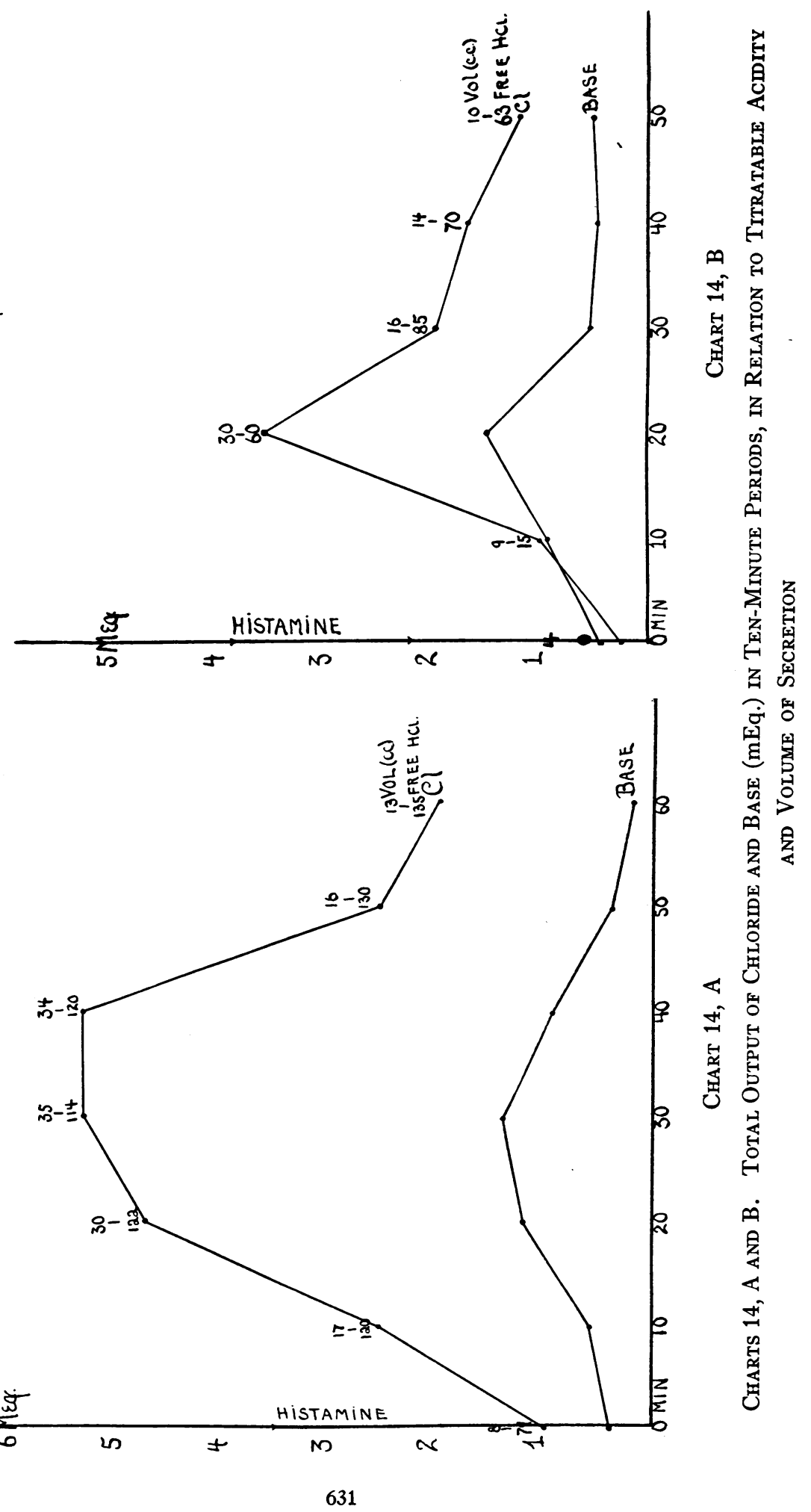




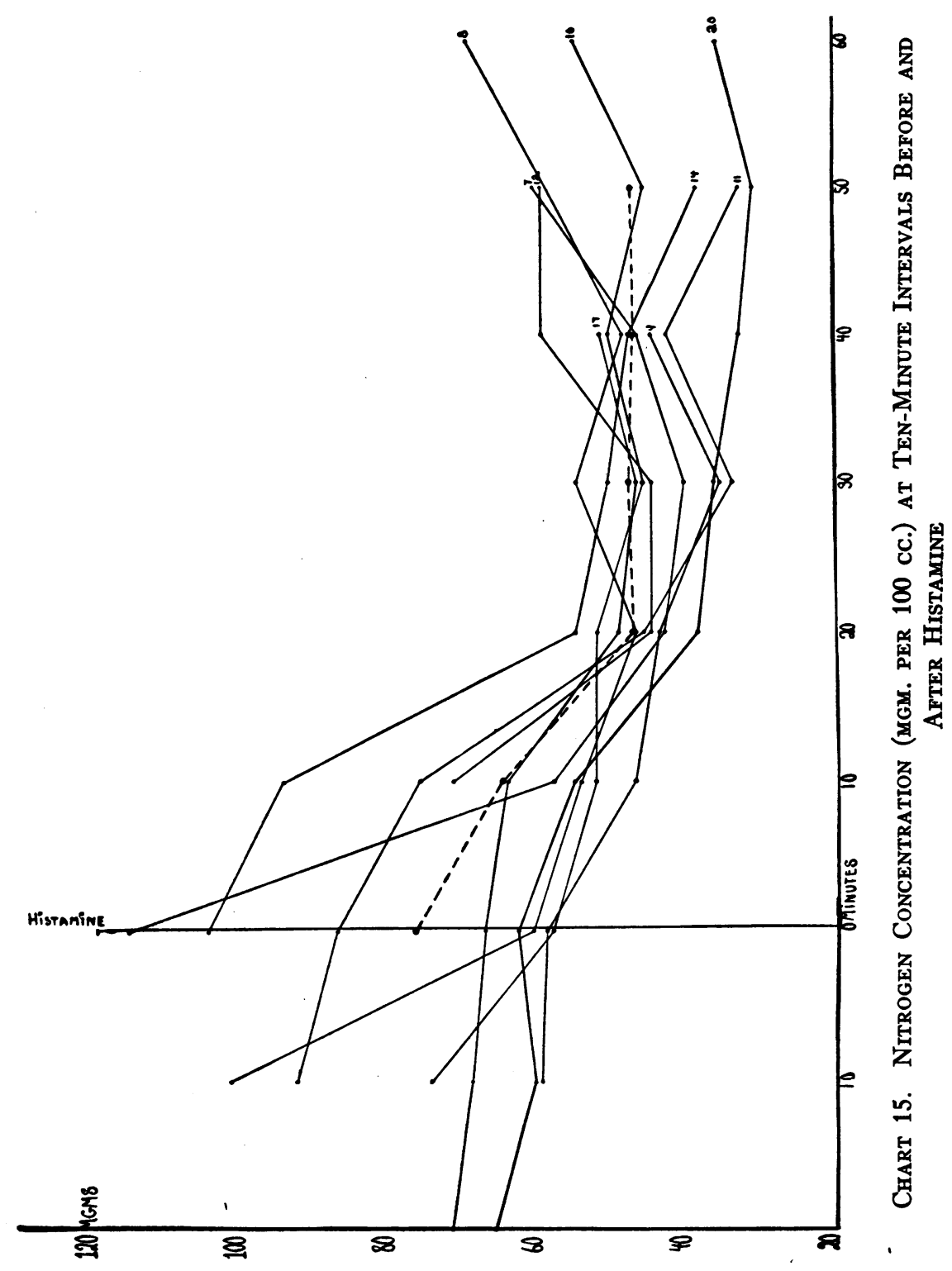


falls. The volume of secretion and titratable free $\mathrm{HCl}$ are also indicated above the chloride line. The importance of taking volume of secretion into account is clearly brought out. In case 24 , for example, during the forty to fifty-minute period the excess of chloride over base is much less than during the preceding period. In spite of this the titratable acidity is slightly higher. This is clearly explained by the fall in volume of secretion from 34 to $16 \mathrm{cc}$.

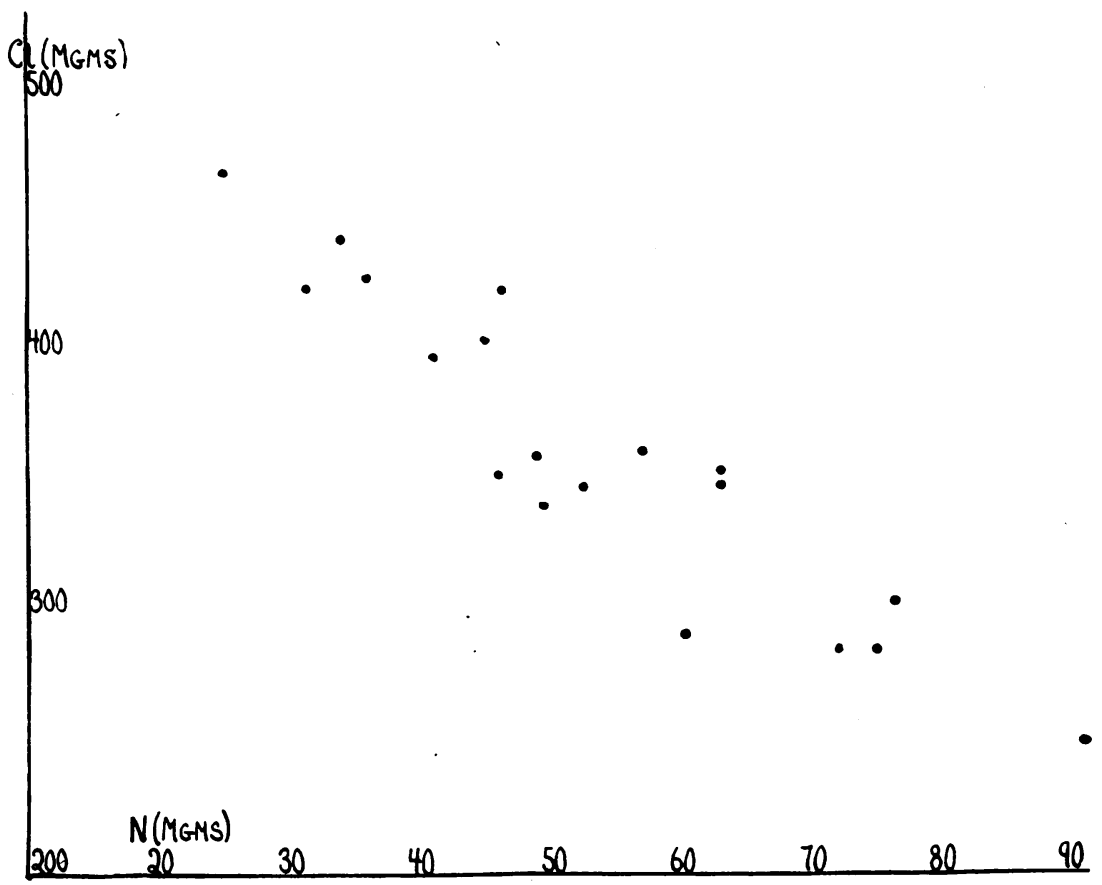

Chart 16. Relation of Concentration of Nitrogen to Concentration of Chloride in Various Specimens

Concentration of nitrogen. Chart 15 shows the figures for concentration of nitrogen in eight cases, and the composite curve (broken line) indicates the general trend of events; there is a distinct fall after stimulation, followed by a sustained low level, and after an hour, a rise. The same reasoning as in the case of base was applied to show that these variations in nitrogen were not due simply to dilution. Chart 16 gives nitrogen values plotted against the chloride concentra- 
tion of the same specimens. A definite inverse relation is evident. Furthermore, as in the case of base, the total amounts of nitrogen

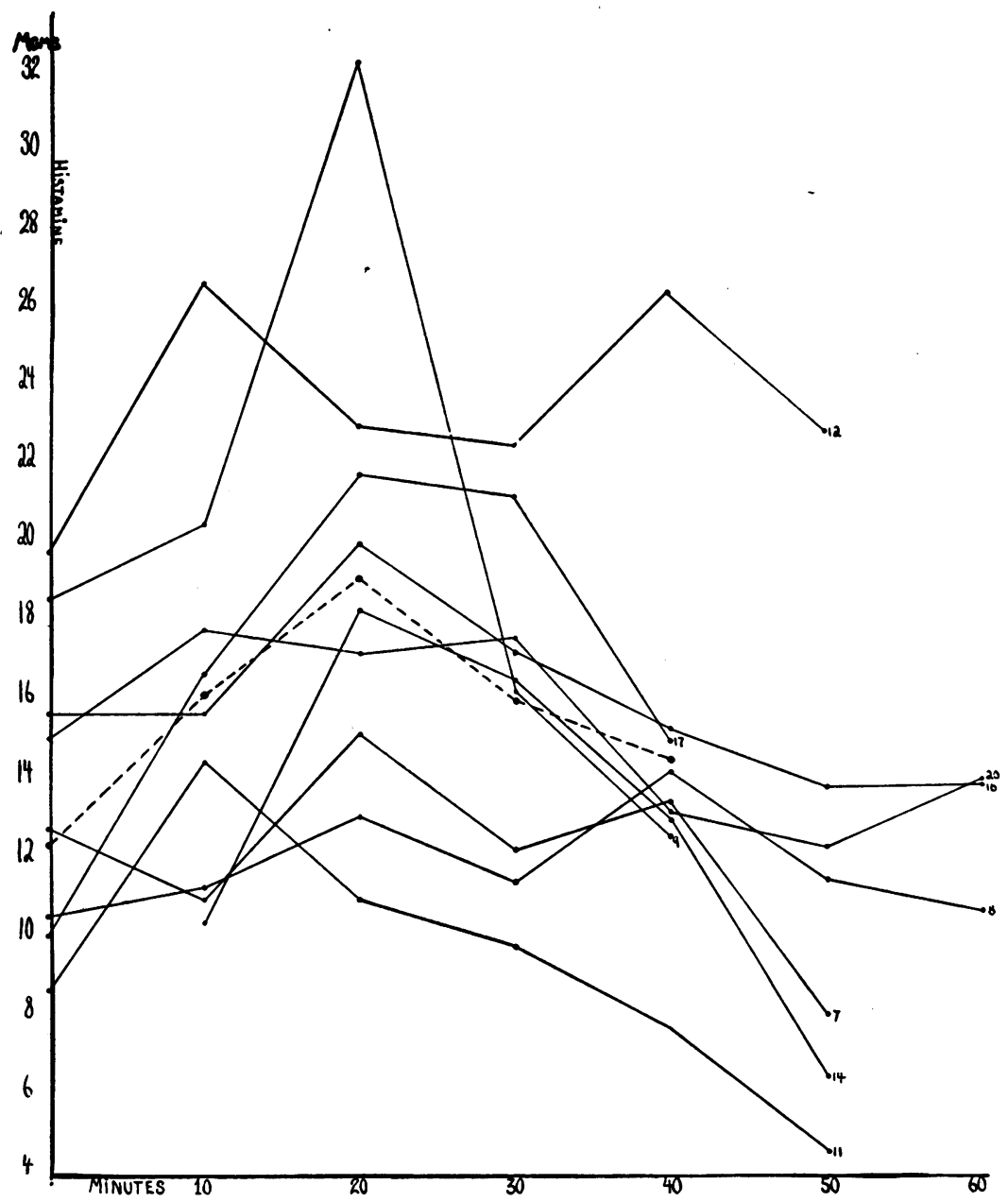

Chart 17. Curves Showing Total Nitrogen (mgm.) of Gastric Juice for Ten-Minute Periods Before and After Histamine

secreted over ten-minute periods in general increase after stimulation (see chart 17). Briefly, all the curves of nitrogen and base are strik- 
ingly similar (see chart 10). This fact seems of importance in so far as such a close relationship suggests a possible association between the secretory mechanisms for the two. The actual values of nitrogen concentration may be compared with those of the blood and are found to be much smaller. Urea nitrogen was estimated in one case (number 16) and represented approximately one-tenth of the total nitrogen.

\section{DISCUSSION}

On the basis of the above facts one may now discuss the sequence of events in gastric secretion. The fasting stomach, in the case of our subjects, under basal conditions, secreted a relatively small amount of juice with low chloride and high base and nitrogen content. After histamine stimulation there was an increase in the volume of secretion with increase in concentration of chloride and of total chloride output, and with decrease in concentration of nitrogen and base but with increase of the total quantity of these substances. The first evidence of cessation of secretion was a fall in the volume of juice with drop in total output of all its elements; later the concentration of nitrogen and base rose and the concentration of chlorides in the mixed juice fell. The importance of determining the total output of the various constituents should be specially emphasized. Unless total quantities are determined one can obtain no accurate idea of the rate of secretion which is the truest index of gastric function; the concentration of chloride, for example, may be the same in two people who, per unit of time secrete very different amounts of chloride.

From the clinical standpoint one is interested in the validity of the titratable acidity as an index of acid secreting capacity of the stomach. Our observations indicate that provided pure gastric juice (i.e., juice undiluted by test deal) is examined the titratable acidity at the height of secretion does furnish such an index inasmuch as it falls short of the actual chloride secretion by a relatively constant amount. Chloride concentration indicates the highest potential acidity of the gastric secretion; the actual free acidity depends upon the amount of base and other neutralizing substance present. Duodenal regurgitation apparently played no part in the present experiments.

We have studied our protocols to see if any light could be thrown on the fundamental mechanism of gastric secretion. No methods have as 
yet been devised which make it possible to analyze the secretion of individual gastric cells or groups of cells; the contents of the tubules represent a composite secretion which may undergo various alterations before actual discharge into the stomach. An analysis of mixed gastric juice is therefore at best far removed from the events which take place at secreting cell surfaces. Most students of gastric physiology believe that at least two types of cell-the peptic and the acid-have different secretory functions. The similarity between our curves for base and nitrogen suggest that these substances are perhaps put out by the same cells, whereas the acid may arise from others. The relation of the curve of peptic activity to the nitrogen curve is now being studied. It may be, as many have suggested (18), that the acid cells secrete an unstable chloride which is hydrolyzed with the liberation of $\mathrm{HCl}$, the base being retained or resorbed. This process is obviously enhanced during active secretion. Base and nitrogen may be secreted by different groups of cells. Be this as it may, in actual fact there is, in our observations, a general relationship between the various elements of gastric secretion which suggests that all of the cells give a coördinated response to histamine stimulation.

\section{SUMMARY}

Curves are presented which show the course of gastric secretion before and after histamine stimulation. The volume of secretion, the concentration of chloride, base and nitrogen and the total chloride, base and nitrogen have been studied. Increase in titratable acidity after stimulation results from greater increase in output of chloride than of base. Nitrogen secretion seems to parallel secretion of base and hence may be related to it; at any rate, nitrogen is actively secreted by the stomach.

\section{BIBLIOGRAPHY}

1. Bloomfield, A. L., and Keefer, C. S., J. Clin. Invest., 1927, iv, 485. The Rate of Gastric Secretion in Man.

2. Bloomfield, A. L., and Keefer, C. S., J. Am. Med. Assoc., 1927, lxxxviii, 707. Clinical Studies of Gastric Function.

3. Bulger, H. A., and Allen, D. S., Proc. Soc. Exp. Biol. and Med., 1927, xxiv, 902. Studies on the Mechanism of Gastric Hydrochloric Acid Secretion. 
4. Carlson, A. J., Physiol. Rev., 1923, iii, 1. The Secretion of Gastric Juice in Health and Disease.

5. Baird, M. McC., Campbell, J. M. H., and Hern, J. R. B., Guy's Hosp. Reports, 1924, lxxiv, 23. The Importance of Estimating Chlorides in Fractional Test Meal Samples.

6. Miller, S., and Smith, F. B., Lancet, 1927, i, 593. The Chlorides of Gastric Contents in Relation to Free Acidity.

7. Bolton, C., and Goodhart, G. W., Lancet, 1922, i, 420. Duodenal Regurgitation into the Stomach During Gastric Digestion.

8. Berglund, H., Wahlquist, H., and Sherwood, K. K., Proc. Soc. Biol. and Exp. Med., 1927, xxiv, 927. Hydrochloric Acid and Total Chlorine Content . of Pure Gastric Juice Produced After Histamine Injection.

9. Gamble, J. L., and McIver, M. A., Proc. Soc. Exp. Biol. and Med., 1926, xxiii, 439. Fixed Base in Gastric Juice.

10. Bloomfield, A. L., and Keefer, C. S., J. Clin. Invest., 1928, v, 295. Gastric Motility and the Volume of Gastric Secretion in Man.

11. Bloomfield, A. L., and Keefer, C. S., J. Clin. Invest., 1928, v, 285. Gastric Acidity: Relation to Various Factors Such as Age and Physical Fitness.

12. Carlson, A. J., The Control of Hunger in Health and Disease. Chicago, 1916.

13. Van Slyke, D. D., J. of Biol. Chem., 1923-24, lviii, 523. The Determination of Chlorides in Blood and Tissues.

14. Stadie, W. C., and Ross, E. C., J. Biol. Chem., 1925, lxv, 735. A MicroMethod for the Determination of Base in Blood and Serum and other Biological Materials.

15. Mathews, A. P., Text Book of Physiological Chemistry. New York, 1925, p. 357.

16. Lim, R. K. S., Matheson, A. R., and Schlapp, W., Quart. J. Exper. Physiol., 1923, xiii, 361. Observations on the Human Gastro-Duodenal Secretions with Special Reference to the Action of Histamine.

17. Bulger, H. A., Peters, J. P., Eisenman, A. J., and Lee, C., J. Clin. Invest., 1926, ii, 213. Total Acid-Base Equilibrium of Plasma in Health and Disease. VII. Factors Causing Acidosis in Chronic Nephritis. A Preliminary Report.

18. Hanke, M. E., and Donovan, P. B., J. Biol. Chem., 1927, lxxiv, p. xxiv. The Organic Chlorides of Tissues and Their Possible Relation to Gastric Hydrochloric Acid Formation. 